\title{
Influence of Spinal Cord Stimulation on the Innervation Pattern of Muscle Fibers in vivo
}

\author{
C. Fournier Le Ray and J. Fontaine-Perus \\ Université de Nantes, Faculté des Sciences et des Techniques, Centre National de la Recherche Scientifique, URA 1340, \\ 44072 Nantes Cedex 03, France
}

In chick embryo, chronic stimulation of the brachial spinal cord at a fast rhythm from days 7 to 18 of development induced an increase in AChE activity sites and ACh receptor (AChR) clusters in slow anterior latissimus dorsi (ALD) muscle. Most AChR clusters and AChE spots were contacted by nerve endings. A previous study showed that such spinal cord stimulation causes changes in ALD muscle properties, especially the appearance of a high proportion of fast type Il fibers (Fournier Le Ray et al., 1989). Analysis of the synaptic pattern in different fiber types of experimental ALD muscle indicated a decrease in the distance between successive AChE spots in slow type III fibers compared to controls, whereas the intersynaptic distance in fast type II fibers was very similar to that in the rare fast fibers developing in control ALD. Fast fibers of experimental muscles exhibited less AChR than did slow fibers. The increased number of neuromuscular junctions in ALD muscle after spinal cord stimulation appeared to be preferentially located in slow fibers.

Electron microscopy showed no change in the number of axons in ALD nerve after spinal cord stimulation. The activity imposed on brachial motoneurons apparently caused termilial sprouting of ALD nerve in target muscle, thus accounting for the increase in neuromuscular contacts in ALD muscle fibers. Differences in the distribution of nerve contacts indicate that the type of muscle fiber innervated may play a critical role in the synaptic pattern during chick embryogenesis.

Functional neuromuscular synapses appear within a few days after motor axons develop in embryonic muscle primordia. In birds, nerves enter limb buds at about $4 \mathrm{~d}$ of incubation (Bennett et al., 1980, 1983), and large junctional ACh receptor (AChR) clusters characteristic of primitive neuromuscular contacts can be observed $24 \mathrm{hr}$ later (Smith and Slater, 1983; Phillips et al., 1985). It is generally assumed that synaptogenesis in avian embryos leads to the establishment of several junctions along muscle fiber. Each synaptic site is then polyinnervated by axons arising from several motoneurons (Bennett and Pettigrew, 1976).

\footnotetext{
Received Feb. 6, 1991; revised June 18, 1991; accepted July 17, 1991.

We thank Dr. E. Bandman and O. Pourquie for generously providing monoclonal antibodies. We are also grateful to $G$. Brochard for excellent technical assistance. This work was supported by the Centre National de la Recherche Scientifique and the Association Francaise contre les Myopathies.

Correspondence should be addressed to C. Fournier Le Ray, Université de Nantes, Faculte des Sciences et des Techniques, CNRS URA 1340, 2 Rue de la Houssiniere, 44072 Nantes Cedex 03, France.

Copyright @1991 Society for Neuroscience $0270-6474 / 91 / 113840-11 \$ 05.00 / 0$
}

During development, the distributed inncrvation of muscle fibers and the polyneuronal innervation of junctions are progressively eliminated, so that most fibers become innervated at a single site by a single motoneuron (for review, see Betz, 1987). However, some fibers retain their distributed innervation, as in anterior latissimus dorsi (ALD) (Ginsborg, 1960), adductor profundus (Barnard et al., 1982), and plantaris (Grim et al., 1985) muscles in adult birds.

The innervation pattern of skeletal muscle fibers has been related to the ability of motoneurons to release ACh (Vrbova et al., 1978). It has been suggested that the first nerve contact with a muscle fiber makes the rest of the sarcolemma refractory to synapse formation (Bennett and Pettigrew, 1974; Kano, 1975) and that refractoriness could be dependent on axon ability to depolarize the remainder of the fiber (Vrbova et al., 1978). Focal innervation occurs if initial nerve contact causes depolarization of the entire fiber. When the nerve ending is unable to provide a propagated action potential, distributed innervation is required to initiate depolarization of the whole sarcolemma (Vyskocil et al., 1971). These observations suggest that the synaptic pattern of muscle fibers depends on the properties of the motor nerve endings that contacted the developing fibers. Khaskiye et al. (1980) and Grim et al. (1989) have demonstrated the determinant influence of motoneurons on synaptic site distribution by showing that innervation in a heterotopically innervated target muscle develops according to the origin of neural primordium rather than to its normal pattern. Conversely, Laing and Lamb (1983) observed no changes in normal synaptic distribution of chick ulnimetacarpalis dorsalis muscle after inappropriate innervation.

Latissimus dorsii muscles in the chick originate from a common primordium (Grim, 1971) and acquire their main features during embryonic development. ALD muscle becomes almost exclusively formed of slow fibers with distributed innervation, whereas posterior latissimus dorsi (PLD) is composed of focally innervated fast fibers (Ginsborg, 1960; Feng et al., 1965). Numerous studies have shown that fiber types appear intrinsically determined at early stages of development. Embryonic muscle fibers seem to develop slow and fast features independently of innervation. In the chick, differentiation of slow and fast fibers occurs after neural tube ablation (Butler et al., 1982; Phillips and Bennett, 1984), and in the rat destruction of innervation prior to the invasion of motor axons into muscles does not prevent the development of different fiber types (Harris et al., 1989; Condon et al., 1990). In vitro studies suggest that myoblasts isolated from embryonic chick limb are heterogeneous and predisposed to express either slow or fast features according to their origin (Fremont et al., 1983; Miller and Stockdale, 1987). 
$\%$ of muscle flbre segments

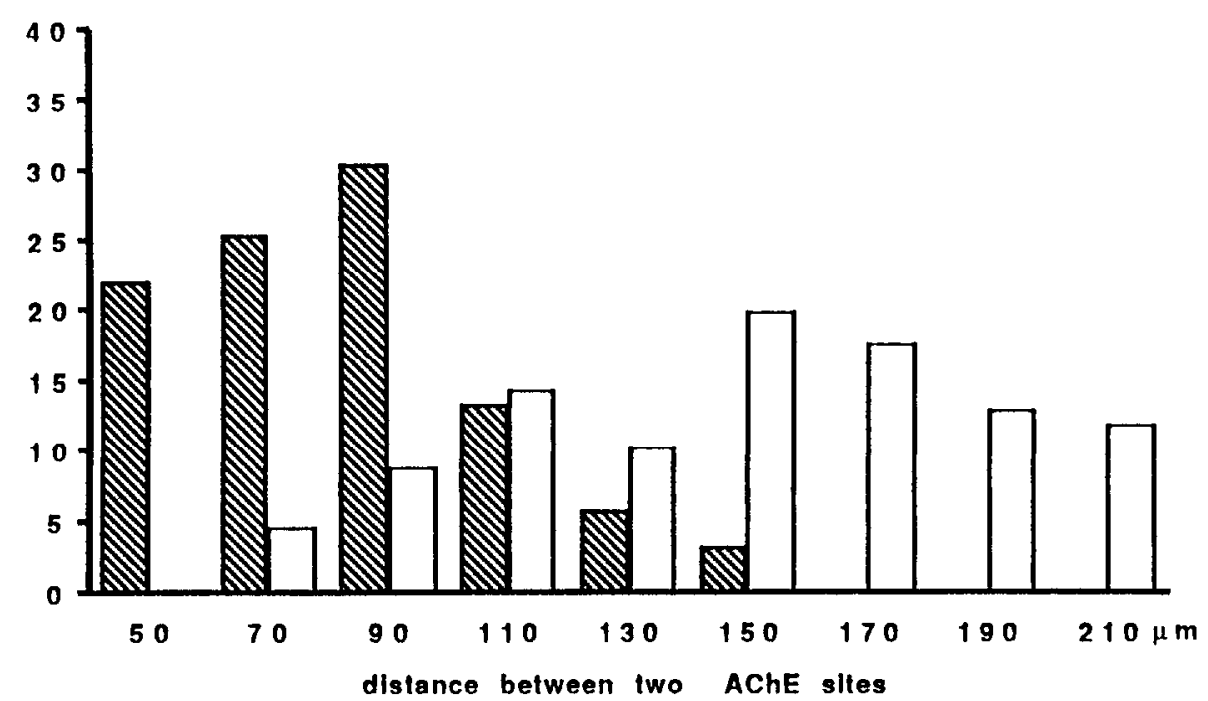

Figure 1. Frequency histogram of distances between two sites of $\mathrm{AChE}$ activity in ALD muscle fibers of 18-d-old control and stimulated chick embryos.
These results suggest that early events of fiber type differentiation do not require nerve contact.

Most experiments to study neuromuscular interactions during embryonic development have involved muscle innervation by heterotopic levels of the neuraxis. We developed a method in chick embryo allowing the activity of motoneurons innervating ALD and PLD muscles to be modified by chronic stimulation of the brachial spinal cord when functional innervation occurs (for review, see Gardahaut et al., 1990). We determined that motoneuron activity plays an important role in differentiation of fast and slow features of muscle fibers (Renaud et al., 1978; Toutant et al., 1979, 1980; Gardahaut et al., 1985, 1990; Fournier Le Ray et al., 1989). For example, activity imposed at a fast rhythm induces the development of a large number of fast fibers in slow ALD muscle at the end of embryogenesis (Fournier Le Ray et al., 1989). In this context, the question arose as to whether the innervation pattern of such experimental muscle was also changed. The present study demonstrates that an activity imposed at a fast rhythm strongly modifies synaptic site and innervation distribution in ALD muscle fibers.

\section{Materials and Methods}

Experiments were performed on outbred Rhode Island chick embryos. Chronic spinal cord stimulation. The method of chronic electrical spinal cord stimulation has been described elsewhere (Renaud et al., 1978). Briefly, perimedullary electrodes were implanted at the brachial level at day 6 of embryonic development, and stimulation was initiated at day 7 . Pulses $(5 \mathrm{msec})$ were delivered at $30 \mathrm{~Hz}$ in $1 \mathrm{sec}$ bursts repeated every 8 sec. Stimulation efficiency was checked as previously described (Fournier Le Ray et al., 1989). If necessary, stimulus voltage was adjusted to maintain effective stimulation. In controls, perimedullary electrodes were implanted but no electrical stimulation was delivered.

Innervation analysis. ALD muscles removed from 15- or 18-d-old control and spinal cord-stimulated embryos were immediately frozen in liquid nitrogen-cooled isopentane. Longitudinal cryostat-cut sections from experimental and control muscles were collected on the same slides.

Postsynaptic acetylcholinesterase (AChE) activity was revealed by the method of Karnowsky and Roots (1964). Sections $(15 \mu \mathrm{m})$ were fixed in $6 \%$ formalin solution (pH 7.2) and incubated in the acetylthiocholinecontaining medium for $30 \mathrm{~min}$ at $4^{\circ} \mathrm{C}$. The distances between AChE- positive end plates were measured at $200 \times$ magnification with an eyepiece micrometer.

AChR and nerve endings were visualized simultaneously. Longitudinal sections ( $7 \mu \mathrm{m}$ thick) were fixed in $6 \%$ formalin solution (pH 7.2), and $\mathrm{AChR}$ were revealed by incubation in tetramethylrhodamine-conjugated $\alpha$-bungarotoxin (TRITC $\alpha$-BGT; Molecular Probes, Inc.) for 1 hr at $4^{\circ} \mathrm{C}(0.5 \mu \mathrm{g} / 100 \mu \mathrm{l}$ of $2 \%$ fetal calf serum-PBS buffer $)$. After washing in $2 \%$ fetal calf serum-PBS buffer ( $\mathrm{pH} \mathrm{7.4)}$ for $30 \mathrm{~min}$, nerve fibers were identificd by immunocytochemistry. Scctions were incubated overnight at $4^{\circ} \mathrm{C}$ with a monoclonal antibody directed against either the $68 \mathrm{kDa}$ neurofilament (NF) subunit (Sigma Chemical Co.) or a membrane-associated molecule of central and peripheral embryonic neurons (an antibody named BEN prepared at the CNRS Institute of Cellular and Molecular Embryology, Nogent sur Marne, France; Pourquie et al., 1990). Sections were rinsed in PBS buffer for $1 \mathrm{hr}$ and incubated with a fluorescein isothiocyanate-labeled goat anti-mouse IgG antibody (Southern Biotechnology Associates, Inc.).

Colocalization of AChR and AChE spots was performed by successive treatments of sections ( $7 \mu \mathrm{m}$ thick) with TRITC $\alpha$-BGT and using the method of Karnowsky and Roots (1964).

Analysis of the innervation pattern in different types of muscle fibers. Simultaneous demonstration of myofibrillar ATPase (mATPase) and postsynaptic $\mathrm{AChE}$ activity was done using a procedure derived from the technique described by Ashmore et al. (1978). After acid preincubation at $\mathrm{pH} 4.2$, longitudinal sections ( $15 \mu \mathrm{m}$ thick) of experimental and control muscles were incubated for $20 \mathrm{~min}$ at $37^{\circ} \mathrm{C}$ in medium containing $35 \mathrm{~mm} \mathrm{CaCl}_{2}$ and $5 \mathrm{~mm} \mathrm{ATP}$ at pH 9.4. After staining of the mATPase reaction, AChE spots were revealed by incubation in medium containing acetylthiocholine for $5 \mathrm{hr}$ at $4^{\circ} \mathrm{C}$. The nomenclature defined by Barnard et al. (1982) was used to classify fiber types in ALD muscle. According to this classification, slow type III fibers were characterized by resistance of their myosin-ATPase activity to both alkali and acid preincubations, whereas fast type II fibers exhibited myosinATPase activity that was inhibited after acid preincubation. In each type of ALD muscle fibers, the distances between AChE-positive end plates were measured again at $200 \times$ magnification with an eyepiece micrometer.

Double labeling of AChR and fast myosin was also performed on longitudinal sections ( $7 \mu \mathrm{m}$ thick) fixed in $6 \%$ formalin solution ( $\mathrm{pH}$ 7.2). AChRs were evidenced as previously described, and the sections were then incubated overnight at $4^{\circ} \mathrm{C}$ with a monoclonal antibody (EB 165 , a generous gift of Dr. Bandman, University of California, Davis; Bandman and Bennett, 1988) directed against fast-myosin heavy chain isoforms. Fluorescein isothiocyanate-labeled goat anti-mouse IgG antibody was used to visualize binding sites (Southern Biotechnology Associates, Inc.).

Analysis of fast-myosin heavy chain isoforms in different muscle fiber 

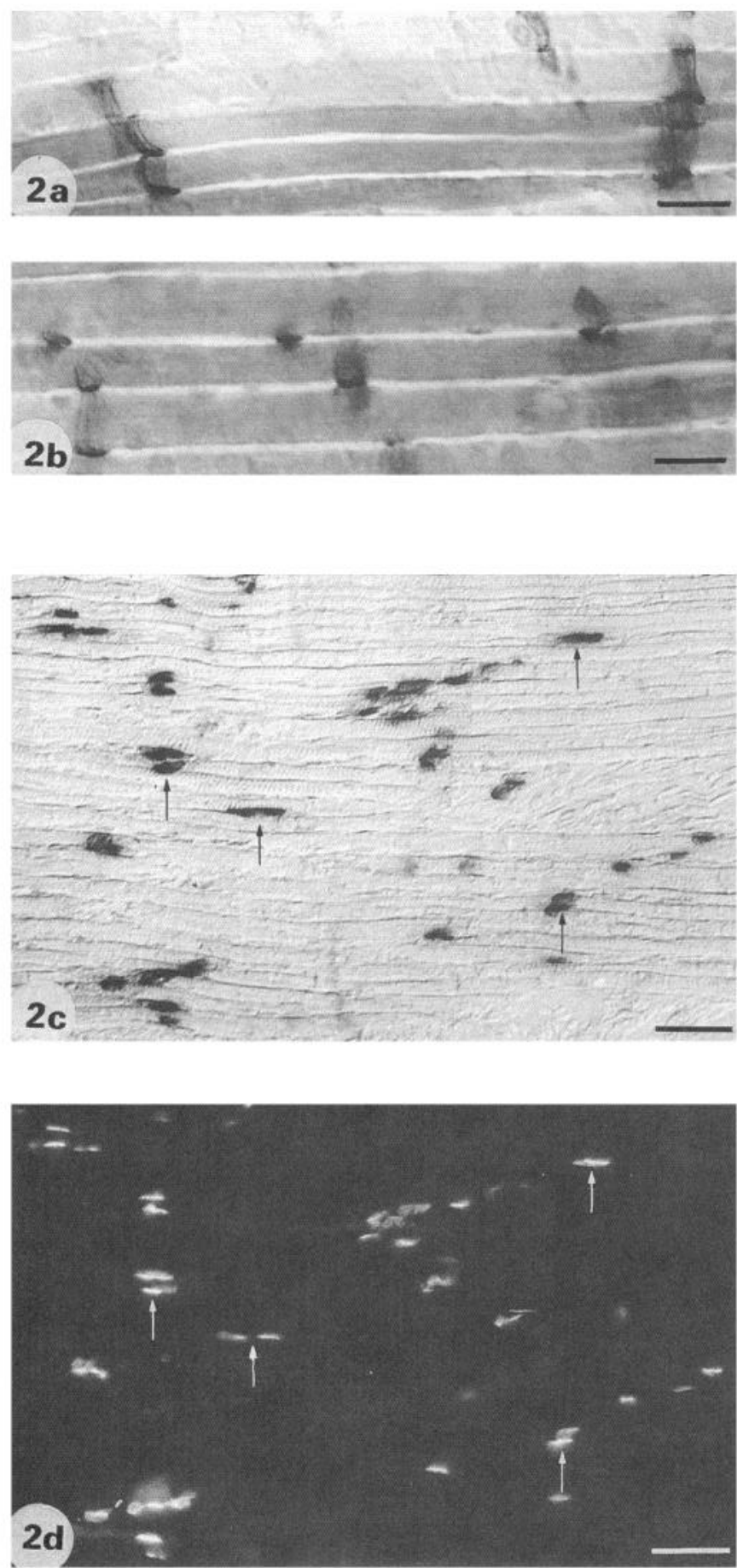

Figure 2. Synaptic site distribution in embryonic ALD muscle fibers. $a$ and $b$, Staining of longitudinal sections for AChE activity in 18-d-old control $(a)$ and stimulated $(b)$ embryos. AChE spots appear more numerous in muscle of stimulated embryos than in controls. As previously shown, fiber diameters are higher in experimental muscle. $c$ and $d$, Simultaneous detection of AChE activity $(c)$ and of $\mathrm{AChR}$ clusters $(d)$ in 18-d-old spinal cord-stimulated embryos. Both reactions are perfectly superposed (arrows), showing that every AChE spot is associated with an AChR cluster. Scale bars: $a$ and $b, 15 \mu \mathrm{m} ; c$ and $d, 30 \mu \mathrm{m}$.

types was performed by demonstrating mATPase activity and EB 165 immunoreactivity on serial cryostat-cut transverse sections $(7 \mu \mathrm{m}$ thick).

Electron microsopy of ALD nerve. ALD and PLD muscles are innervated from the latissimus dorsi nerve arising from the dorsal part of the brachial plexus (Van Den Berge, 1975). It has been shown that the
Table 1. Number of axons and Schwann cells in ALD nerves of control and spinal cord-stimulated embryos

\begin{tabular}{lcc} 
& $\begin{array}{c}\text { Control embryo } \\
\text { day } 18(n=4)\end{array}$ & $\begin{array}{c}\text { Stimulated } \\
\text { embryo days } \\
7-18(n=4)\end{array}$ \\
\hline Promyelin axons 1 & $65 \pm 16$ & $70 \pm 12$ \\
Promyelin axons 2 & $143 \pm 30$ & $104 \pm 19$ \\
Myelinated axons & $301 \pm 35$ & $399 \pm 43$ \\
Total number of axons & $1333 \pm 43$ & $1484 \pm 233$ \\
Schwann cell number & $98 \pm 14$ & $88 \pm 10$ \\
\hline
\end{tabular}

$n$, Number of embryos in which one ALD nerve was examined.

branching pattern of this nerve is not constant from one animal to another (Bourgeois and Toutant, 1982). In some cases, only one ramus emerges from the dorsal branch of two brachial plexuses and innervates the ALD muscle; in other cases, two distinct rami are observed, one innervating the ALD muscle and the other both ALD and PLD muscles. Embryos in which only one ramus innervates the ALD muscle were selected for this study. ALD nerves from 18-d-old control and spinal cord-stimulated embryos were always dissected $2 \mathrm{~mm}$ from the muscle. Nerves were fixed by immersion in $5 \%$ glutaraldehyde in $0.1 \mathrm{~m}$ phosphate buffer ( $\mathrm{pH} 7.4)$ for $30 \mathrm{~min}$ at room temperature, rinsed in the same buffer, and postfixed in cold $1 \% \mathrm{OsO}_{4}$ in $0.1 \mathrm{M}$ phosphate buffer. After dehydration and immersion overnight in propylene oxide: Epon (1:1), nerves were embedded in Epon and sectioned. Thin sections stained with uranyl acetate and lead citrate were observed with a Hitachi electron microscope. Axon counts were done on panoramic photomontages of nerve transverse sections $(7300 \times)$.

Statistical analyses. All values are given as mean \pm SEM. Statistical analyses were performed using Student's $t$ test $(p<0.05$ for tests of significance).

\section{Results}

\section{Influence of spinal cord stimulation on distribution of neuromuscular junctions in ALD muscle}

Distribution of AChE activity spots. AChE spots were examined on longitudinal sections of muscles from 15- and 18-d-old experimental and control embryos. Quantification was done on 250 fibers per muscle, five muscles being observed in each series. Since the length over which a fiber could be observed ranged between 400 and $1200 \mu \mathrm{m}$ from one section to another, the mean distance between two AChE activity spots was determined using two different methods: (1) measuring between two AChE spots on fibers with a minimal length of $800 \mu \mathrm{m}$, and (2) counting the total number of spots between two AChE activity sites over the entire length of every fiber measured in a muscle. This second procedure ensured that fiber fragments devoid of $\mathrm{AChE}$ spots were not omitted. Both methods gave identical results in control as well as stimulated embryos, indicating that the distribution of AChE activity sites in muscle fibers was regular at this development stage.

In 15-d-old control embryos, the mean distance between two AChE activity spots was $136.5 \pm 33 \mu \mathrm{m}$, and in 18-d-old controls it was $146.7 \pm 34 \mu \mathrm{m}$ (range, 70-210) (Fig. 1). Chronic spinal cord stimulation at a fast frequency $(30 \mathrm{~Hz})$ from days 7 to 15 resulted in a $25 \%$ decrease in the mean distance between two AChE spots $(100.5 \pm 4$ vs. $136.5 \pm 33 \mu \mathrm{m} ; p<0.001)$. This decrease reached $35 \%$ in 18 -d-old stimulated embryos $(96$ \pm 4 vs. $146.7 \pm 34 \mu \mathrm{m} ; p<0.001)$, with values ranging between 50 and $150 \mu \mathrm{m}$ (Fig. 1). These results demonstrate that spinal cord stimulation at a fast rhythm from day 7 to the end of the embryonic period increases the number of AChE spots (Fig. $2 a, b)$. The fact that $33 \%$ of muscle fibers in 18-d-old embryos 

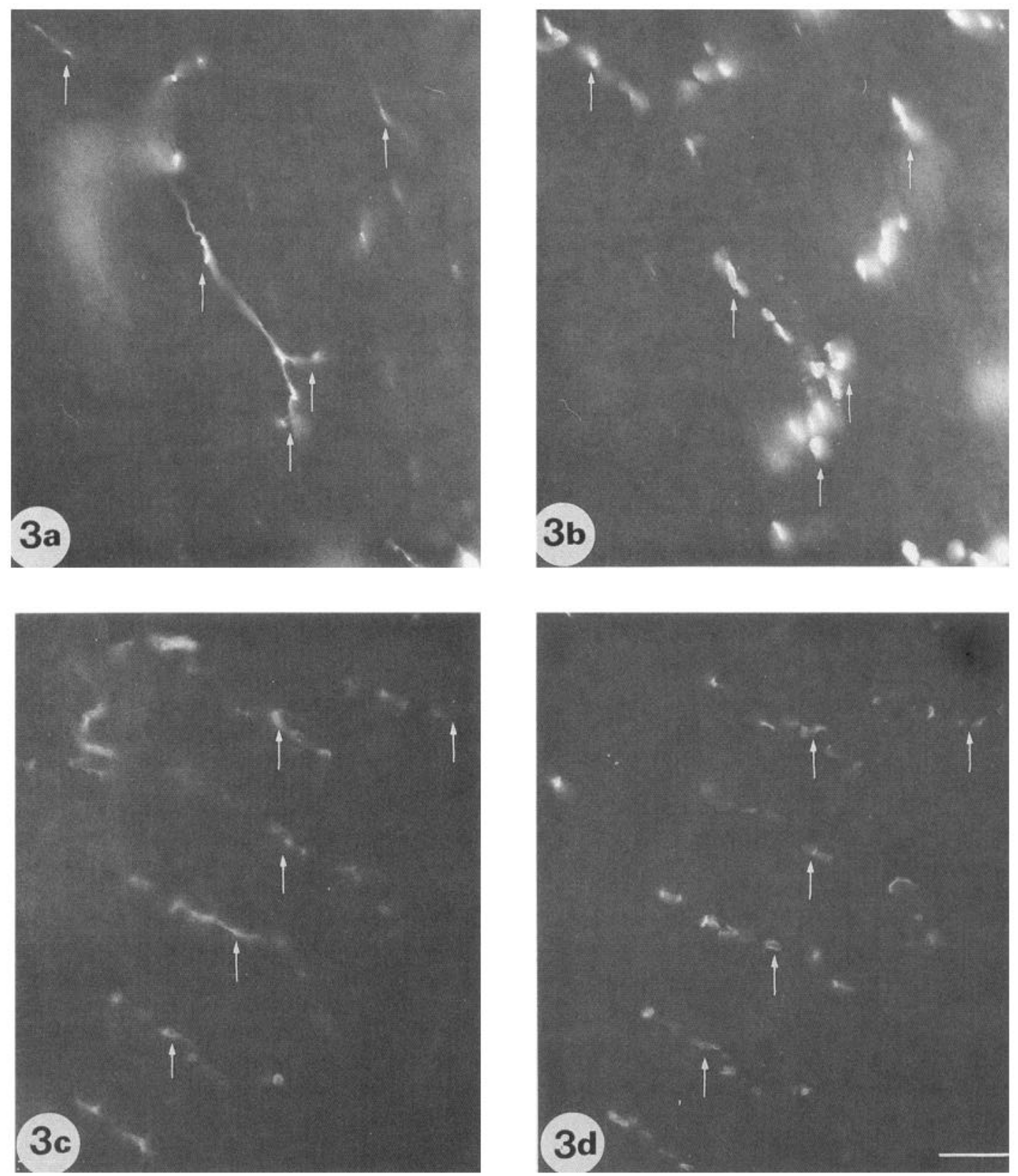

Figure 3. Innervation of synaptic sites in ALD muscle of 18-d-old spinal cord-stimulated embryos: simultaneous visualization of NF ( $a$ ) or BEN (c) immunocytochemistry and TRITC $\alpha$-BGT $(b, d)$. Arrows indicate that the AChR clusters are contacted by nerve terminals. Scale bar, $25 \mu$ m.

had distances between $\mathrm{AChE}$ spots around the frequency mode of distribution versus $20 \%$ in control ALD (Fig. 1) would indicate that the variability between AChE activity sites decreases in experimental muscles.

Distribution of $A C h R$ and nerve endings. Muscle sections were first treated simultaneously to identify sites of AChE activity and $\alpha$-BGT that binds to AChR. These postsynaptic elements were found to be colocalized (Fig. $2 c, d$ ).

To determine whether the newly formed postsynaptic sites in ALD muscles of stimulated embryos were innervated, these sites were revealed by TRITC $\alpha$-BGT and nerve endings were labeled immunocytochemically with NF (Fig. $3 a, b$ ) or BEN antibody (Fig. 3c,d). Comparison of the figures arising from control and stimulated ALD muscles showed a clearly higher density of nerve endings in the latter (Fig. 4). The number of AChRs colocalized with a BEN-labeled profile in ALD sections of spinal cord-stimulated embryos was determined. For each section, counts were done in 10-15 selected fields, and the number of AChR clusters was related to the entire surface of the section. Ninety-eight percent of AChRs were associated with a BENlabeled profile in ALD of experimental embryos (56,307 \pm 3092 of colocalized AChRs vs. $857 \pm 74$ of noncolocalized AChRs; $n=3$ ). These results demonstrate that spinal cord stimulation at a fast rhythm induced an increase in motor nerve endings establishing contacts with ALD muscle fibers.

\section{Influence of spinal cord stimulation on distribution of} neuromuscular junctions in different fiber types of ALD muscle A previous study (Fournier Le Ray et al., 1989) showed that spinal cord stimulation at a fast rhythm between day 7 and the 

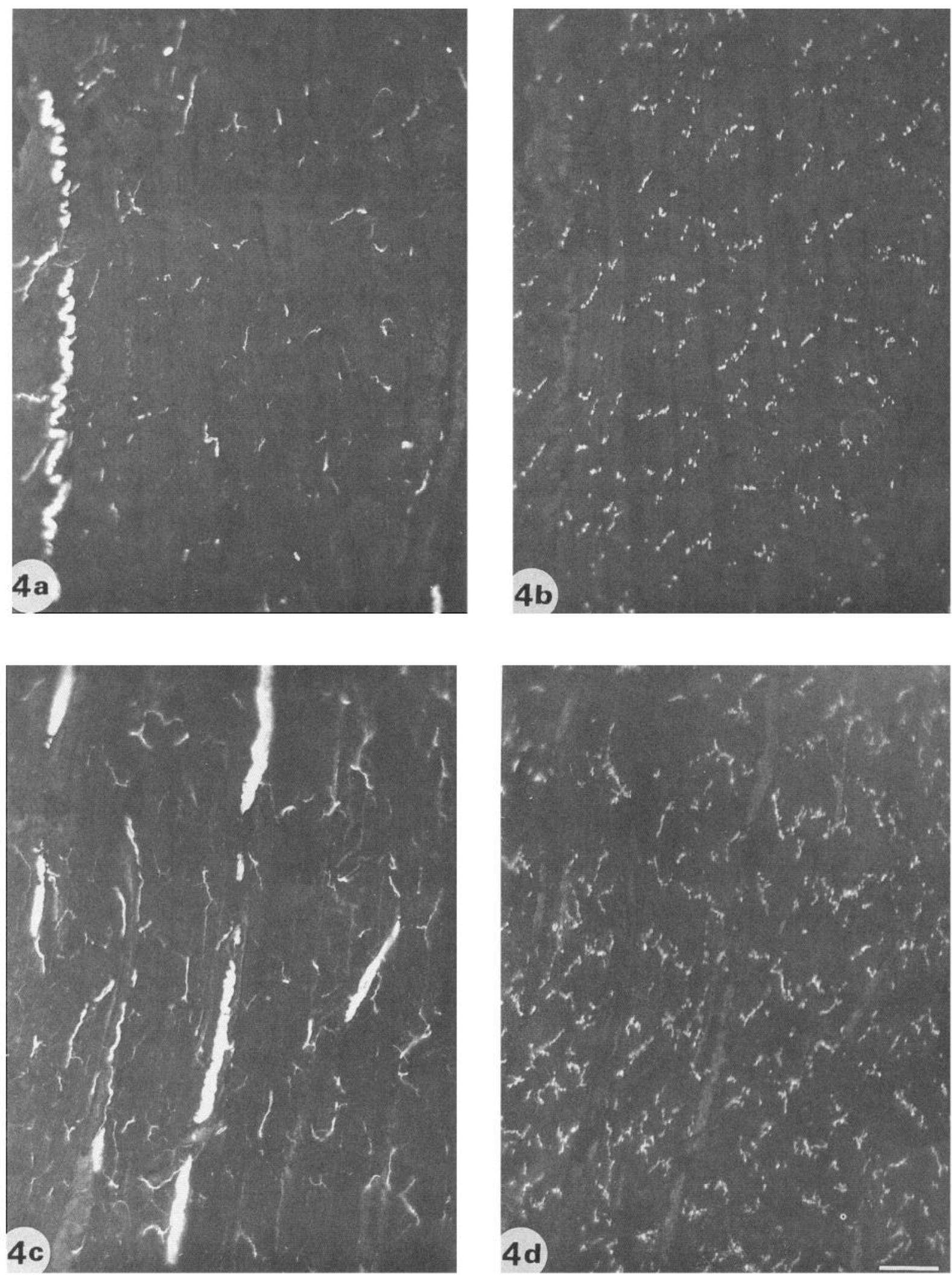

Figure 4. Colocalization of nerve terminals and AChR clusters on longitudinal sections of embryonic ALD muscle fibers: double labeling with NF antibody $(a, c)$ and with TRITC $\alpha$-BGT $(b, d)$ in 18-d-old control $(a, b)$ and stimulated $(c, d)$ embryos. Comparison between $a$ and $c$ illustrates a higher density of nerve fibers in $c$, and comparison between $b$ and $d$ clearly shows an increased number of AChR clusters after stimulation $(d)$. Scale bar, $150 \mu \mathrm{m}$. 
$\%$ of muscle fibre segments
Fast-type II fibres

Slow-type III fibres

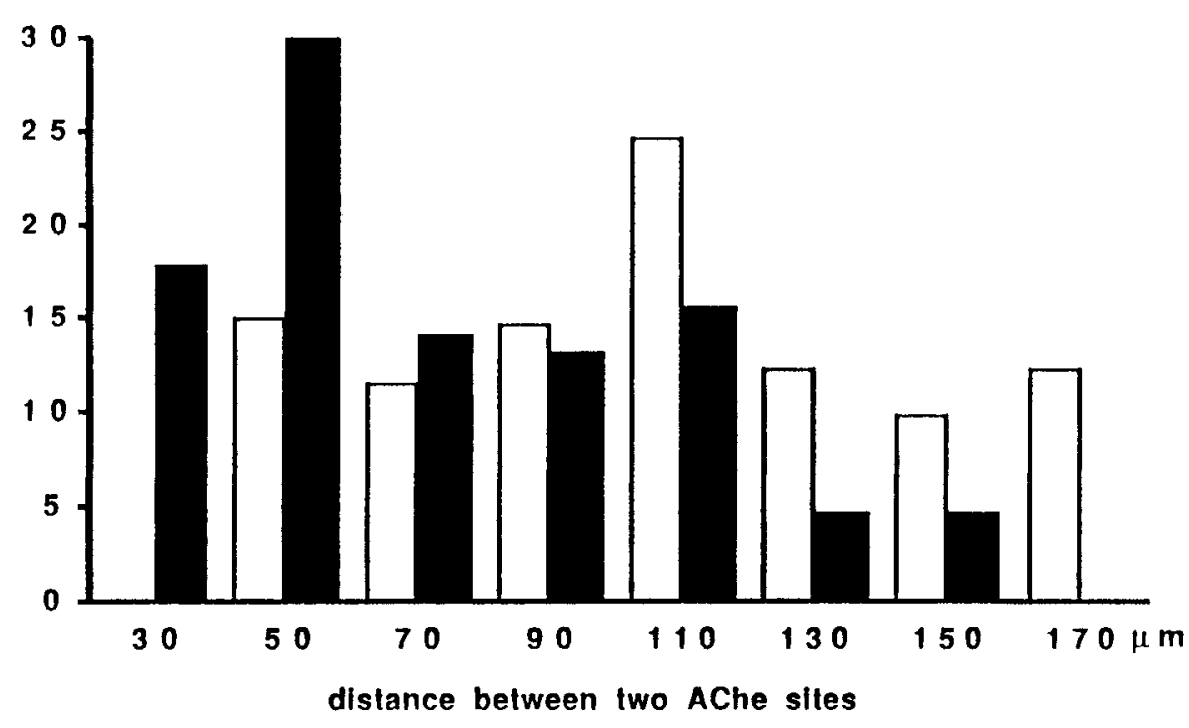

Figure 5. Frequency histogram of distances between two sites of AChE activity in the different fiber types of ALD muscle in 18-d-old stimulated embryos. end of the embryonic period produces changes in ALD muscle properties, especially the appearance of a high proportion of fast fibers (type II according to Barnard et al., 1982) at day 18 of development. In this context, we analyzed the synaptic pattern of the different fibers observed in ALD muscles after spinal cord stimulation.

Distribution of AChE activity spots. The mean distance between two AChE activity spots in different categories of fibers in control and experimental muscles was determined by simultaneous detection of $\mathrm{mATPase}$ and AChE activities. The quantitative methods used were identical to those previously described.

ALD muscles of stimulated embryos contain about $30 \%$ fast type II fibers and 70\% slow type III fibers at the end of the embryonic period, whereas control muscles are almost entirely composed of type III fibers (Fournier Le Ray et al., 1989). In our experimental muscles, the distance between two AChE activity spots in fast type II fibers was very similar to that observed in the rare fast fibers of control ALD [138 $\pm 2 \mu \mathrm{m}$ (72 fibers) vs. $151 \pm 36 \mu \mathrm{m}$ (25 fibers)]. However, a $40 \%$ decrease in the distance between two AChE activity spots was observed in slow type III fibers of ALD muscle as compared to controls [84 \pm 2 $\mu \mathrm{m}$ ( 65 fibcrs) vs. $146 \pm 34 \mu \mathrm{m}$ (165 fibers)]. The mean distance in fast fibers of experimental muscles was greater than that in slow fibers (Fig. 5). Thus, the decrease in the distance between two AChE activity spots observed in the entire muscle after spinal cord stimulation concerned slow type III fibers on which supernumerary neuromuscular junctions appeared to be preferentially located.

$A C h R$ distribution. Longitudinal sections were simultaneously labeled with anti-fast-myosin antibody (EB 165) and TRITC $\alpha$-BGT in order to determine AChR distribution in different fiber types in experimental muscles. Fibers were classified as fast if they stained strongly throughout their length with antifast-myosin antibody and as slow if they showed no staining.

Monoclonal antibody EB 165 has an epitope found in both embryonic and adult fast-myosin heavy chains (Cerny and Bandman, 1987; Bandman and Bennett, 1988). At the end of embryonic development, only the rare fast type II fibers were positively stained with EB 165 in ALD muscle. A significant increase in EB 165-positive fibers was observed after spinal cord stimulation (Fig. 6a). Immunofluorescent fibers were proved to be the fast type previously identified (Fournier Le Ray et al., 1989), as shown by mATPase activity (Fig. $6 b, c$ ).

AChR distribution was different in slow and fast fibers of experimental ALD muscle. Fast type II fibers strongly reacted with EB 165 antibody and exhibited fewer AChRs than nonimmunoreactive slow type III fibers (Fig. $6 d, e$ ). The innervation pattern was not modified in the many fast fibers induced in ALD muscle of stimulated embryos. Thus, the increase in the number of neuromuscular junctions induced in ALD muscle by spinal cord stimulation at a fast rhythm was preferentially distributed in slow fibers. These results are perfectly consistent with those described above concerning supernumerary AChE spots in slow fibers. As most AChRs were found to be colocalized with nerve processes, electron microscopy analysis was performed to count the axons in ALD nerve of control and experimental embryos.

\section{Influence of spinal cord stimulation on differentiation of ALD nerve}

At day 18, embryonic ALD nerve contained four distinct classes of axons (Fig. 7a): (1) the largest axons, isolated from small tightly packed ones enclosed in Schwann cell cytoplasm $\left(\mathrm{pm}_{1}\right)$, (2) unmyelinated axons enclosed in their own Schwann cell cytoplasm $\left(\mathrm{pm}_{2}\right),(3)$ myelinated axons $(\mathrm{m})$, and (4) unmyelinated axons. Separate axons within bundles $\left(\mathrm{pm}_{1}\right)$ as well as singly enclosed axons $\left(\mathrm{pm}_{2}\right)$ have been defined as "promyelin" axons (Reier and Hugues, 1972). ALD nerve from 18-d-old control embryo contained about $20 \%$ myelinated and $14 \%$ promyelin axons (Table 1). No increase in the total number of axons in ALD nerve was observed in stimulated embryos as compared to controls (Table 1). In this case, the increase in motor nerve endings and neuromuscular junctions in experimental ALD muscle would indicate that the effect of stimulation on the innervation pattern was terminal sprouting. Nevertheless, ALD 

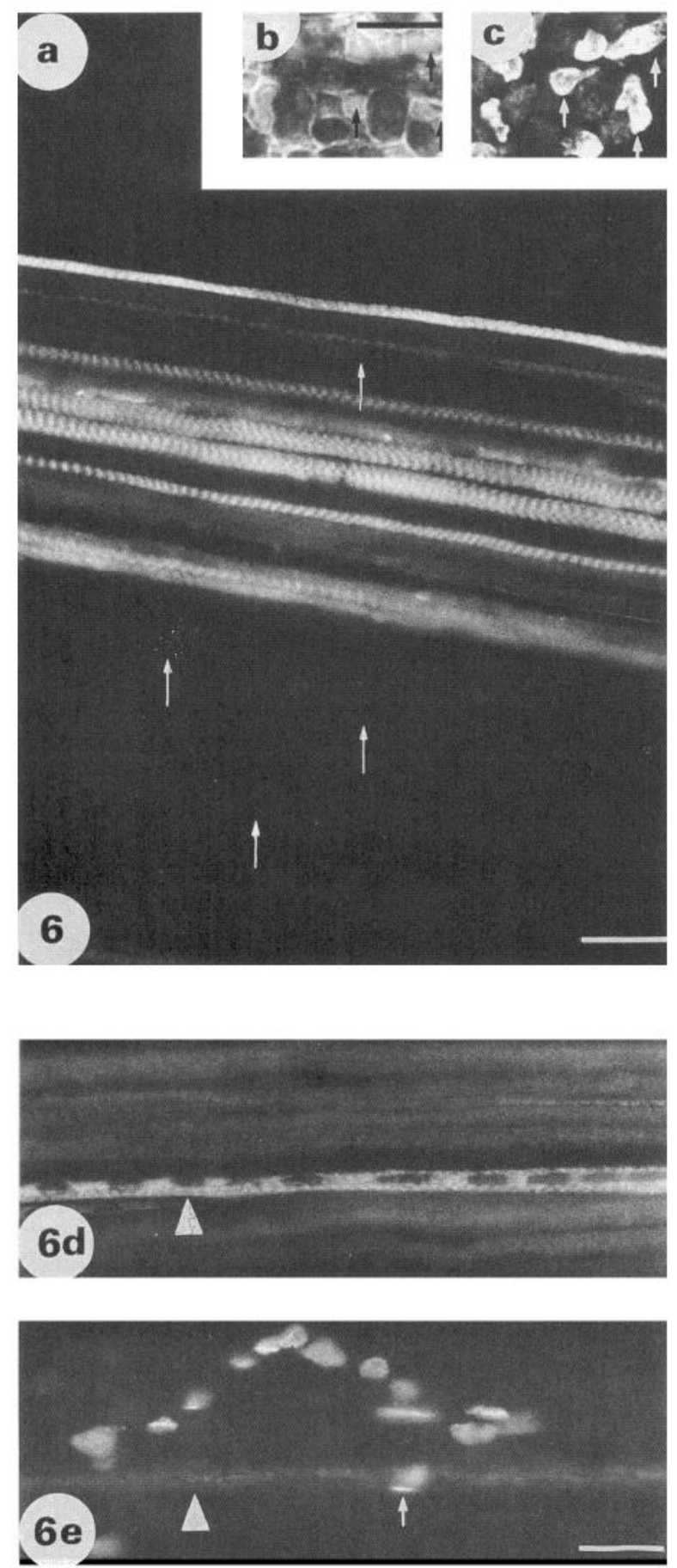

Figure 6. Synaptic site distribution in different fiber types of ALD muscle from 18-d-old stimulated embryos. $a$, Immunoreaction on longitudinal sections with the anti-fast-myosin antibody EB 165. A high proportion of fibers appear immunoreactive; some others (arrows) are negative. $b$ and $c$, Treatment of two successive sections stained for mATPase activity $(b)$ and EB 165 antibody $(c)$. Arrows indicate that the fast type II fibers positively react with the EB 165 antibody. $d$ and $e$, Immunofluorescence of fast-type fibers with EB 165 monoclonal antibody $(d)$ and TRITC $\alpha$-BGT labeling of AChR clusters ( $e$; same longitudinal section). Synaptic sites appear less numerous in immunoreactive fast-type fibers than in the negative ones. An arrow indicates the AChR cluster revealed on the EB 165-positive fiber (head of arrow). Scale bars: $a, d$, and $e, 25 \mu \mathrm{m} ; b$ and $c, 70 \mu \mathrm{m}$. nerve from stimulated embryo had $29 \%$ myelinated axons, and the ratio of myelinated axons to promyelin axons was increased compared to controls (2.30 vs. 1.45) (Table 1, Fig. $7 a, b)$. It is very likely that chronic stimulation does not modify the number of axons in ALD nerve but speeds up the myelination process.

\section{Discussion}

Our results indicate that an induced change in motoneuron activity during the innervation process can modify the synaptic pattern of ALD muscle. Chronic spinal cord stimulation at a fast rhythm from day 7 to the end of embryonic development results in an increase in $\mathrm{AChE}$ activity spots as compared to controls. These AChE spots are associated with AChR clusters and are colocalized with nerve endings. A fast pattern of activity imposed on embryonic motoneurons thus produces increased neuromuscular contacts in slow ALD muscle. The influence of neuromuscular activity on the differentiation of motor innervation has been previously studied in fast PLD muscle of chick embryo (Renaud et al., 1978; Toutant et al., 1979, 1980; Gardahaut et al., 1990). It was found that spinal cord stimulation at a low frequency induces multiple AChE sites and AChR clusters along PLD muscle fibers (Renaud et al., 1978; Toutant et al., 1980). These results, taken together, suggest that spinal cord stimulation, regardless of the rhythm imposed, can cause an increase in synaptic sites in both slow and fast muscles.

In chick embryo, neuromuscular blockade of movement at day 5 of development leads to a considerable increase in AChR clusters $24 \mathrm{hr}$ later, most of which are associated with nerve endings (Dahm and Landmesser, 1991). This change in the rate of synapse formation is accompanied by enhanced branching of motor axons in target muscles (Dahm and Landmesser, 1988) and inhibition of motor neuron death in the lateral motor column of the spinal cord (for review, see Oppenheim, 1989). Subsequent development of paralyzed embryos is characterized by an increase in axons per motor nerve (Ding et al., 1983; Bourgeois et al., 1986) and a reduction in muscle fibers (Harris, 1981; Fredette and Landmesser, 1991). This results in an increase in neuromuscular junctions per muscle fiber at the end of embryogenesis (Ding et al., 1983; Oppenheim et al., 1989). There are apparent similarities between the effects obtained in paralysis experiments and in our stimulation system since these two procedures eventually induce an increase in end plates per myofiber. However, it must be emphasized that chronic spinal cord stimulation does not affect the early events of neuromuscular synaptogenesis in chick embryo. There was no change in the number of motoneurons in the lateral motor column of the brachial spinal cord in stimulated embryos (C. Fournier Le Ray and J. Fontaine-Perus, unpublished observations), and the increase in synaptic sites only occurred in experimental ALD muscle on and after day 15 of development (the end of the motorneuron cell death period). Moreover, chronic spinal cord stimulation from days 7 to 18 of embryonic development did not modify the number of axons in ALD and PLD motor nerves (Toutant et al., 1981; the present study) or the number of muscle fibers in ALD and PLD (Renaud et al., 1983; Fournier Le Ray et al., 1989). Therefore, the increase in synapse formation induced by spinal cord stimulation, without modification in the number of axons and muscle fibers, could have been due to sprouting in nerve endings.

There are two feasible explanations for the origin of this terminal sprouting. Intramuscular branching of motor axons may have been enhanced, as described by Dahm and Landmesser 

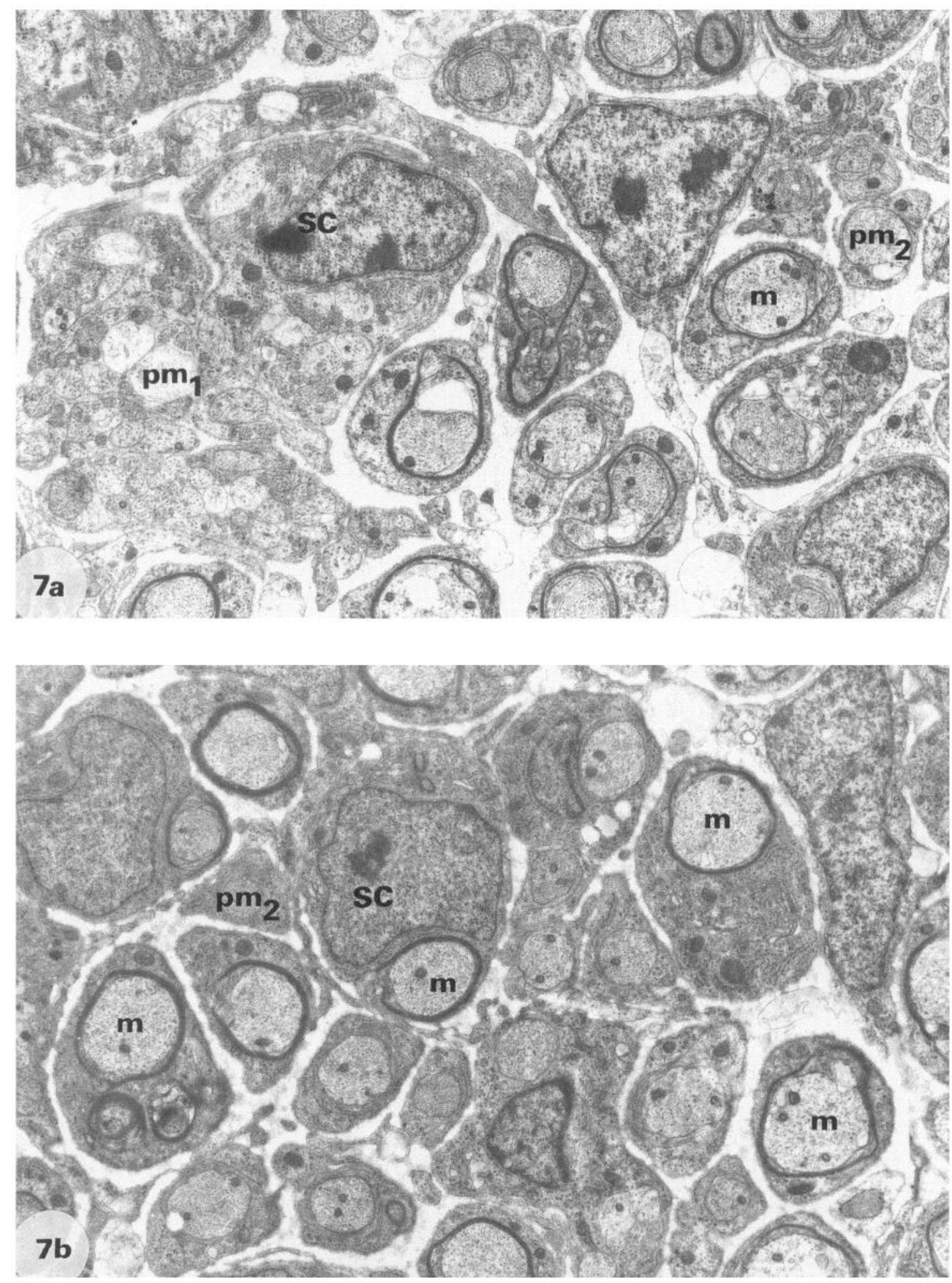

Figure 7. Tranverse sections of ALD nerves from 18-d-old control ( $a$ ) and stimulated $(b)$ embryos. $S C$, Schwann cell nuclei; $p m_{l}$, separate axons within a bundle; $p m_{2}$, singly enclosed axons. Myelinated axons $(m)$ appear more numerous in ALD nerve after central stimulation $(b)$. Magnification, $7500 \times$.

(1988), or hyperinnervation could have resulted from a simple redistribution of axonal branches, with no change in the size of the axonal arbors of motor nerves, as in the case of normal development (Bourgeois and Toutant, 1982). Bourgeois et al.
(1986) have shown that chronic electrical stimulation of chick embryo accelerates the regression of focal polyinnervation in PLD muscle. In experimental embryos, axonal branches retracted from end plates may thus form supernumerary stable 
junctions along muscle fibers under the influence of imposed activity. Both inhibition and stimulation of neuromuscular activity can induce a considerable increase in neuromuscular synapses. The increase occurs before the onset of motoneuron cell death in the first case (Dahm and Landmesser, 1991) and after in the second case. Thus, activity blockade plays a crucial role in regulating motoneuron survival, whereas activity stimulation may act later on in regulating nerve branching.

Factors other than neuromuscular activity are presumably involved in control synapse stabilization during development, including muscle fiber type. In adult birds, innervation of the different fiber types is precise and orderly, with each motor unit containing fibers of only one type (Jones et al., 1987a,b; Betz et al., 1990). Reinnervation experiments conducted in newborn rats have demonstrated that motor ncurons can recognize and selectively reinnervate muscle fibers (Soileau et al., 1987). In chick embryo, foreign innervation of target muscles performed by limb or spinal cord reversals has shown that differentiating myotubes are selectively innervated by motoneurons of the appropriate type (Vogel and Landmesser, 1987). Our results indicate that terminal sprouting of ALD nerve induced by spinal cord stimulation from days 7 to 18 of embryogenesis almost exclusively concerns slow fibers of target muscle.

In experimental ALD muscle, a great number of fast type II fibers and a high content of fast-myosin light chains have been observed (Fournier Le Ray et al., 1989). As indicated here, these fibers strongly react with an antibody against fast myosin (EB 165). Localization of EB 165 and TRITC $\alpha$-BGT conjugate shows that fast immunoreactive fibers have the same number of synaptic contacts as do the rare fast fibers observed in controls. Converscly, ncgative slow fibers possess a greater number of AChR clusters than do control slow fibers. In adult birds, fast type II fibers are typically focally innervated (Barnard et al., 1982). Some studies of PLD muscle development indicate that type II fibers receive their mature focal innervation as early as day 10 of embryogenesis (Burden, 1977; Betz et al., 1980; Toutant et al., 1980). However, Phillips and Bennett (1987a,b) have described a transient development of distributed AChR clusters in fast type II fibers of embryonic triceps brachii pars humeralis and PLD muscles. The discrepancy between these results could relate to the minimal length of fiber fragments used for AChR counts (see Phillips and Bennett, 1987a). For these authors, all immature avian muscle fibers require distributed innervation to ensure a propagated action potential at early stages of development. Synaptic elimination then occurs in fast fibers at the end of the embryonic period in order to establish focal innervation. Our study shows that the rare fast fibers in developing ALD muscle are multiinervated at the end of embryonic development. This multiinervation is almost entirely eliminated later on in development since only a few of the fast fibers that persist in the adult maintain more than one synaptic site (Rouaud and Toutant, 1982). The fast fibers in ALD muscle of stimulated embryo present the same pattern as in controls. They are thus characterized by multiinervation that will be eliminated during postnatal development. These numerous fast fibers do not accept additional synapses, whereas slow fibers are able to receive hyperinnervation. Therefore, in our experimental system, the innervation pattern would appear to be selective, depending on the type of fiber innervated. It can thus be concluded that muscle fiber features have an influence on determination of the synaptic pattern in chick embryonic development.
Our results indicate that stimulation of motoneurons as early as day 7 of embryogenesis produces a change in the innervation of ALD muscle that is only apparent in late embryonic development. This phenomenon was previously noted in the case of numerous fast fibers not detected in experimental muscle before day 16 of development (Fournier Le Ray et al., 1989). Such late changes in response to an early experimental modification of innervation have already been demonstrated by Harris et al. (1989), who describe a crucial period of nerve dependence for myoblasts that occurs several days before their actions are apparent. The authors relate this phenomenon to the behavior of late nerve-dependent populations of myoblasts that, by fusing with myotubes, could introduce nuclei with new genetic programs. Such a mechanism could also be involved in our experimental system. Our previous experimental results led us to hypothesize that the development of fast fibers in ALD muscle of stimulated embryos could be related to changes in the differentiation of secondary myoblasts (Fournier Le Ray et al., 1989). These myoblasts have been shown to contain nervedependent individuals (Fredette and Landmesser, 1991) that could give rise to fast fibers in ALD muscle of experimental embryos. The expression of "late" genes in association with myoblasts may account not only for the muscle fiber type changes in experimental ALD at the end of embryogenesis but also for the distribution of innervation in the different fiber types. Phillips and Bennett (1989) have suggested that the elimination of excess distributed AChR clusters in fast muscle fibers in chick embryo is due to the preferential accumulation of nuclei at a single cluster on each fiber. Thus, a modulation of gene expression in myotubes could also be responsible for the heterogeneous distribution of nerve endings in different fiber types of experimental muscle.

It would appear from our study that the increased activity imposed on brachial motoneurons by spinal cord stimulation during early embryogenesis induces terminal sprouting in target muscles, thereby demonstrating the role of neurons in the establishment of the innervation pattern during embryonic development. However, as the distribution of nerve endings differs according to muscle fiber type, the nature of muscle fibers could also have an influence on this pattern.

\section{References}

Ashmore CR, Kikuchi T, Doerr L (1978) Some observations on the innervation patterns of different fiber types of chick muscle. Exp Neurol 58:272-284.

Bandman E, Bennett T (1988) Diversity of fast myosin heavy chain expression during development of gastrocnemius, bicep brachii and posterior latissimus dorsi muscles in normal and dystrophic chickens. Dev Biol 130:220-231.

Barnard EA, Lyles JM, Pizzey JA (1982) Fibre types in chicken skeletal muscles and their changes in muscular dystrophy. J Physiol (Lond) 331:333-354.

Bennett MR, Pettigrew AG (1974) The formation of synapses in striated muscle during development. J Physiol (Lond) 241:515-545.

Bennett MR, Pettigrew A (1976) The formation of neuromuscular synapses. Cold Spring Harbor Symp Quant Biol 40:409-424.

Bennett MR, Davey DF, Uebel KE (1980) The growth of segmental nerves from the brachial myotomes into the proximal muscles of the chick forelimb during development. J Comp Neurol 189:335-357.

Bennett MR, Davey DF, Marshall JJ (1983) The growth of nerves in relation to the formation of premuscle cell masses in the developing chick forelimb. J Comp Neurol 21 5:217-228.

Betz H, Bourgeois JP, Changeux JP (1980) Evolution of cholinergic proteins in developing slow and fast skeletal muscles in chick embryo. J Physiol (Lond) 302:197-218.

Betz WJ (1987) Motoneuron death and synapse elimination in ver- 
tebrates. In: The vertebrate neuromuscular junction, pp 117-162. New York: Liss.

Betz WJ, Ribchester RR, Ridge RMAP (1990) Competitive mechanisms underlying synapse elimination in the lumbrical muscle of the rat. J Neurobiol 21:1-17.

Bourgeois JP, Toutant M (1982) Innervation of avian latissimus dorsi muscles and axonal outgrowth pattern in the posterior latissimus dorsi motor nerve during embryonic development. J Comp Neurol 208:115.

Bourgeois JP, Toutant M, Gouze JL, Changeux JP (1986) Effect of activity on the selective stabilization of the motor innervation of fast muscle posterior latissimus dorsi from chick embryo. Int J Dev Neurosci 4:415-429.

Burden S (1977) Development of the neuromuscular junction in the chick embryo: the number, distribution, and stability of acetylcholine receptors. Dev Biol 57:317-329.

Butler J, Cosmos E, Brierley J (1982) Differentiation of muscle fiber types in aneurogenic brachial muscles of the chick embryo. J Exp Zool 224:65-80.

Cerny L, Bandman E (1987) Expression of myosin heavy chain isoforms in regenerating myotubes of innervated and denervated chicken pectoral muscle. Dev Biol 119:350-362.

Condon K, Silberstein L, Blau HM, Thompson WJ (1990) Differentiation of fiber types in aneural musculature of the prenatal rat hindlimb. Dev Biol 138:275-295.

Dahm L, Landmesser L (1988) The regulation of intramuscular nerve branching during normal development and following activity blockade. Dev Biol 130:621-644.

Dahm L, Landmesser L (1991) The regulation of synaptogenesis during normal development and following activity blockade. J Neurosci $11: 238-255$.

Ding R, Jansen JKS, Laing NG, Tonnesen H (1983) The innervation of skeletal muscle in chickens curarized during early development. J Neurocytol 12:887-919.

Feng TP, Wu WY, Yang FY (1965) Selective reinnervation of a slow or a fast muscle by its original motor supply during regeneration of a mixed nerve. Sci Sin 14:1717-1720.

Fournier Le Ray C, Renaud D, Le Douarin GH (1989) Change in motor neurone activity modifies the differentiation of a slow muscle in chick embryo. Development 106:295-302.

Fredette BJ, Landmesser LT (1991) A reevaluation of the role of innervation in primary and secondary myogenesis in developing chick muscle. Dev Biol 143:19-35.

Fremont PH, Fournier Le Ray C, Le Douarin GH (1983) In vitro differentiation in the absence of nerve of avian myoblasts derived from slow and fast rudiments. Cell Differ 13:325-340.

Gardahaut MF, Rouaud T, Renaud D, Le Douarin G (1985) Influence of spinal cord stimulation upon myosin light chain and tropomyosin subunit expression in a fast muscle (posterior latissimus dorsi) of the chick embryo. J Muscle Res Cell Motil 6:769-781.

Gardahaut MF, Fontaine-Perus J, Le Douarin GH (1990) Spinal cordmuscle relations: their role in neuro-muscular development in birds. Int J Dev Biol 34:181-189.

Ginsborg BL (1960) Some properties of avian skeletal muscle fibers with multiple neuromuscular junctions. J Physiol (Lond) 154:581598.

Grim M (1971) Development of the primordia of the latissimus dorsi muscle of the chicken. Folia Morphol (Prague) 19:252-258.

Grim M, Christ B, Jacob HJ, Vrabcova M (1985) Chick and quail specific pattern of endplates and fibre-types in the plantaris muscle. Physiol Bohemoslov 34:247-249.

Grim M, Nensa K, Christ B, Jacob HJ, Tosney KW (1989) A hierarchy of determining factors controls motoneuron innervation. Experimental studies on the development of the plantaris muscle (PL) in avian chimeras. Anat Embryol 180:179-189.

Harris AJ (1981) Embryonic growth and innervation of rat skeletal muscles. I. Neural regulation of muscle fibre numbers. Philos Trans R Soc Lond [Biol] 293:257-277.

Harris AJ, Fitzsismons RB, McEwan JC (1989) Neural control of the sequence of expression of myosin heavy chain isoforms in foetal mammalian muscles. Development 107:751-759.

Jones SP, Ridge RMAP, Rowlerson A (1987a) The nonselective innervation of muscle fibres and mixed composition of motor-units in a muscle of neonatal rat. J Physiol (Lond) 386:377-394.

Jones SP, Ridge RMAP, Rowlerson A (1987b) Rat muscle during postnatal development: evidence in favour of no interconversion between fast- and slow-twitch fibres. J Physiol (Lond) 386:395-406.

Kano M (1975) Development of excitability in embryonic chick skeletal muscle cells. J Cell Physiol 86:503-510.

Karnowsky MJ, Roots L (1964) A "direct coloring" thiocholine method for cholinesterases. J Histochem Cytochem 12:219-222.

Khaskiye A, Toutant JP, Toutant M, Renaud D, Le Douarin GH (1980) Effect of heterotopic innervation on the development of synaptic pattern in chick embryo muscles. Arch Anat Microsc Morphol Exp 69: $135-146$.

Laing NG, Lamb AH (1983) The distribution of muscle fibre types in chick embryo wings transplanted to pelvic region is normal. J Embryol Exp Morphol 78:67-82.

Miller JB, Stockdale FE (1987) What muscle cells know that nerves don't tell them. Trends Neurosci 10:325-329.

Oppenheim RW (1989) The neutrophic theory and naturally occurring motoneuron death. Trends Neurosci 12:252-255.

Oppenheim RW, Bursztajn S, Prevette D (1989) Cell death of motoneurons in the chick embryo spinal cord. XI. Acetylcholine receptors and synaptogenesis in skeletal muscle following the reduction of motoneuron death by neuromuscular blockade. Development 107 331-341.

Phillips WD, Bennett MR (1984) Differentiation of fiber types in wing muscles during embryonic development: effect of neural tube removal. Dev Biol 106:457-468.

Phillips WD, Bennett MR (1987a) Elimination of distributed acetylcholine receptor clusters from developing fast-twitch fibres in an avian muscle. J Neurocytol 16:1-10.

Phillips WD, Bcnnctt MR (1987b) Elimination of distributed synaptic acetylcholine receptor clusters on developing avian fast-twitch muscle fibres accompanies loss of polyneuronal innervation. J Neurocytol 16:785-797.

Phillips WD, Bennett MR (1989) The distribution of intracellular acetylcholine receptors and nuclei in developing avian fast-twitch muscle fibres during synapse elimination. J Neurocytol 18:241-255.

Phillips WD, Lai K, Bennett MR (1985) Spatial distribution and size of acetylcholine receptor clusters determined by motor nerves in developing chick muscles. J Neurocytol 14:309-325.

Pourquie O, Coltey M, Thomas J, Le Douarin N (1990) A widely distributed antigen developmentally regulated in the nervous system. Development 109:743-752.

Reier PJ, Hugues AF (1972) An effect of neonatal radiothyroidectomy upon nonmyelinated axons and associated Schwann cells during maturation of the mouse sciatic nerve. Brain Res 41:263-283.

Renaud D, Le Douarin GH, Khaskiye A (1978) Spinal cord stimulation in chick embryo: effects on development of the posterior latissimus dorsi muscle and neuromuscular junctions. Exp Neurol 60:189200.

Renaud D, Gardahaut MF, Rouaud T, Le Douarin GH (1983) Influence of chronic spinal cord stimulation upon differentiation of $\beta$ muscle fibers in a fast muscle (posterior latissimus dorsi) of the chick embryo. Exp Neurol 80:157-166.

Rouaud T, Toutant JP (1982) Histochemical properties and innervation pattern of fast and slow tonic fibre types of the anterior latis simus dorsi muscle of the chick. Histochem J 14:415-428.

Smith MA, Slater CR (1983) Spatial distribution of acetylcholine receptors at developing chick neuromuscular junctions. J Neurocytol 12:993-1005.

Soileau LC, Silberstein L, Blau HM, Thompson WJ (1987) Reinnervation of muscle fiber types in the newborn rat soleus. J Neurosci 7 : $4176-4194$

Toutant JP, Toutant M, Renaud D, Le Douarin GH (1979) Enzymatic differentiation of muscle fiber types in embryonic latissimus dorsii of the chick: effects of spinal cord stimulation. Cell Differ 8:375-382.

Toutant M, Bourgeois JP, Toutant JP, Renaud D, Le Douarin GH, Changeux JP (1980) Chronic stimulation of the spinal cord in developing chick embryo causes the differentiation of multiple clusters of acetylcholine receptor in the posterior latissimus dorsi muscle. Dev Biol 76:384-395.

Toutant M, Toutant JP, Renaud D, Le Douarin GH (1981) Effects of spinal cord stimulation on the differentiation of posterior latissimus dorsi nerve in the chick embryo. Exp Neurol 72:267-280.

Van Den Berge JC (1975) Aves myology. In: The anatomy of the domestic fowl (Sisson, Grossman, eds), pp 1802-1848. Philadelphia: Saunders. 
Vogel M, Landmesser L (1987) Distribution of fiber types in cmbryonic chick limb muscles innervated by foreign motoneurons. Dev Biol 119:481-495.

Vrbova G, Gordon T, Jones R (1978) Nerve-muscle interaction. London: Chapman and Hall.
Vyskocil R, Vyklicky L, Huston R (1971) Quantum content at the neuromuscular junction of fast muscle after cross-union with the nerve of slow muscle in the chick. Brain Res 26:443-445. 